\title{
CONDIÇÕES DE TRABALHO COM TEATRO NA Rede PÚBlica de ENSINO: SAIR DE BAIXO OU ENTRAR NO JOGO
}

\author{
Sergio Coelho Borges Farias ${ }^{1}$
}

"Impressionante como eles são perturbados. Eles gritam, falam alto, agridem uns aos outros. A sétima $B$ é mais civilizada, mas a sétima $A$ é um inferno. O professor tem que chamar atenção o tempo todo, praticamente gritar. Não respeitam ninguém, todos os professores passam por isso. Alguns deles não ligam mais pra bagunça, tentam abstrair. O pior é que tem alguns alunos que gostam da aula e querem estudar, mas não conseguem ouvir. Eu levo um apito. Funciona um pouco, depois não adianta, volta tudo. Eu dei pra subir na cadeira. Agora dou aula em pé, em cima da cadeira. Aí eles param, ficam olhando...”.

Esta é uma narrativa de uma estudante de Licenciatura em Teatro, cursando a sua última disciplina, que inclui estágio em escola da rede pública de ensino. Os estagiários fazem relatos desse tipo na sessão semanal realizada na Faculdade de Educação. Um colega dela, que realiza estágio na mesma escola, depois de registrar as dificuldades em termos de espaço apropriado às aulas de teatro, complementa: "Para eles pararem eu dou tapa na mesa. Só funciona assim”. Mostra como faz, e prossegue: "quando eu era aluno, eu era inquieto, perturbava, mas era eu e mais dois ou três. Agora quatro ficam atentos e todos os outros perturbam!”. Outro acrescenta: “Eu tenho na minha sala 32 gritantes!”.

Boa parte da aula de Metodologia do Ensino de Teatro, que dura cerca de três horas, é ocupada pelo depoimento dos estagiários acerca do andamento

${ }^{1}$ Universidade Federal da Bahia - UFBA do estágio o que inclui comentários acerca da dispersão, agitação, agressividade, scbfar@gmail.com 
indisciplina, seja lá como se chame esse jeito de ser de boa parte dos jovens que (ainda) freqüentam as escolas públicas. Por que isso ocorre? Como lidar com isso? Até quando um professor consegue agüentar? Vai continuar ou vai desistir?

O contraponto aparece nos relatos de quem faz estágio no CEFET, em uma ou outra escola que adota um sistema mais definido de incentivo ao estudo e controle de comportamento, ou de quem atua com grupos especiais, criados através de projetos, com as aulas funcionando em turno complementar ao do curso regular. Nesse último caso, são turmas menores, compostas por quem opta por fazer teatro e não está ali “obrigado”. Em algumas escolas da rede pública as condições de trabalho para o professor de teatro não são tão críticas, embora exista, ainda, a indisposição, incompreensão ou intolerância de diretores e coordenadores pedagógicos para com a arte no currículo.

Salas com chão sujo e de dimensões inadequadas ao número de alunos, situadas junto às outras salas da escola onde o silêncio é importante, e a falta quase absoluta de material didático são agravantes para a questão principal da presente reflexão: a dispersão, a agressividade e a falta de interesse pelos estudos por parte dos estudantes. Em que medida essas condições de trabalho são elementos impeditivos ou desafiadores para o professor?

O incômodo causado pelo barulho feito nas aulas de teatro, com os exercícios corporais de liberação e de expressão vocal, e mesmo com trabalhos criativos em grupos nos quais muitos falam ao mesmo tempo, vem sendo um dos motivos para gestores evitarem colocar o teatro como componente curricular nos projetos pedagógicos das escolas que dirigem. Aulas de artes visuais e desenho geométrico causam menos problemas, e muitas vezes são somente elas (também muito importantes) as escolhidas para o cumprimento da lei que obriga a inclusão do "ensino de arte".

Jogo dramático (play way), performance, jogo teatral, drama, happening, peça didática, montagens de espetáculos, além da dança e da música, enfim, todas as formas de composição artística cênica que impliquem na produção sonora (vista como bagunça) e na retirada do estudante da tradicional carteira, restritiva e limitativa do movimento, são vistas em geral como elementos nocivos, nos já conturbados ambientes da rede pública de ensino.

Na Faculdade de Educação, a segunda parte de cada aula de Metodologia é destinada à apresentação do que o estagiário se propõe a realizar no campo, incluindo os exercícios e jogos preparatórios e os textos a serem encenados. A terceira parte fica para a discussão de um ou dois textos selecionados num conjunto de mais de cinqüenta indicados, buscando-se relacionar o que se está estudando no campo teórico com a prática desafiadora na escola. 
Ao final do semestre cada estudante de Metodologia compõe um relatório de estágio que inclui uma introdução contendo concepções sobre Teatro na Educação, informações sobre as condições de trabalho na escola onde o estágio foi realizado, o Plano de Curso, os Planos de Aula, a descrição analítica do processo, que inclui necessariamente a apresentação de um produto cênico, os critérios e instrumentos de avaliação, e os resultados. Cada estagiário escolhe no início do semestre um estudante de sua turma que apresente alguma dificuldade de interação (timidez, agressividade, necessidade de aparecer etc.) para acompanhar com maior cuidado, ajudando-o a superar a dificuldade e registrando seus avanços e dificuldades.

É no curso de Metodologia de Ensino de Teatro que o futuro professor (muitos já atuam na rede escolar através de contratos provisórios) intensifica sua preparação no campo pedagógico, que envolve preliminarmente os fundamentos psicológicos, a organização do sistema de ensino e a didática.

A discussão de textos sobre Teatro na Educação indicados para leitura é uma constante nas aulas de Metodologia. Antes do estágio na rede oficial de ensino os concluintes de Licenciatura realizam um experimento de ensino de teatro na educação não formal ou informal e passam por um treinamento de exercício docente ministrando aulas para seus colegas na própria Faculdade. As atividades, chamadas micro-aulas, duram de 25 a 30 minutos e versam sobre temas livremente escolhidos dentro de três campos: história do teatro, interpretação teatral e técnicas do espetáculo. Cada estudante escolhe um tema em cada campo. Após a micro-aula expositiva (que pode conter uma demonstração prática), os colegas comentam o desempenho didático, identificando os acertos e sugerindo elementos para aperfeiçoamento. A coordenação do professor de Metodologia é importante para esclarecimentos e para complementação das análises. Numa turma de 15 estudantes de Metodologia, por exemplo, tem-se 45 aulas para serem analisadas.

Cada estudante de Metodologia compõe uma espécie de dossiê em três pastas, contendo exercícios e jogos, textos sobre arte na educação e textos que podem vir a ser encenados nas escolas.

É com essa base preparatória que os desafios e os dilemas que aparecem no estágio são discutidos. As questões éticas aparecem nos relatos, entremeadas com as problemáticas técnicas e de política pública. Uma pergunta acompanha, então, as reflexões: qual a postura adequada para o profissional da educação diante das condições críticas da rede pública de ensino? 
Os resultados dos esforços para a universalização do acesso à escola não se fizeram acompanhar de melhoria na qualidade de ensino. O caminho pode ser a devida valorização da profissão docente, o estímulo a excelência e a cobrança de resultados, sem falar na destinação dos recursos financeiros necessários por parte da gestão pública. Os índices começam a melhorar, mas o Brasil ainda está longe de superar o atraso registrado no ranking mundial referente à qualidade da educação básica.

O desinteresse dos estudantes pela aprendizagem (não quer dizer que na rede privada isso não ocorra, mas a realidade é outra) é tão marcante que se tem a impressão de que os que ainda não evadiram estão ali devido aos resquícios da crença de que é estudando que se consegue emprego melhor e que se progride socialmente. Estão ali porque os pais os obrigam a freqüentar a escola, embalados pela referida crença. Não é a toa que muitas escolas têm aparência de prisões, com grades reforçadas que por um lado dificultam as depredações e roubos de equipamentos, mas por outro lado impedem os estudantes de fugir nos inúmeros períodos de aulas vagas devido às ausências de professores. Mas parece que os estudantes estão ali motivados também pelo encontro com os colegas. Conversam o tempo todo, brincam, paqueram, aprendem todas aquelas bobagens importantes na convivência e parecem não se importar com a falta de aulas, infelizmente muito comum na rede pública de ensino.

Não cabe generalizar, pois existe um pequeno índice de reprovação, mas o que ocorre em geral é uma facilidade do estudante passar de ano, embalada pela preocupação dos governos em demonstrar uma eficiência do sistema. Professores desmotivados pela desvalorização da profissão docente acabam reduzindo seus investimentos para promover a aprendizagem, aprovando em massa em troca de trabalhos de equipe, muitas vezes copiados na internet, ou testes curtos com questões reveladas com antecedência, além da famosa nota de participação. Os professores evitam passar trabalhos e exercícios para serem feitos em casa, já que isso implicará na avaliação posterior de centenas deles, para o que não terá tempo, já que em geral o professor trabalha em mais de uma escola para sobreviver.

O controle de freqüência às aulas assim como as reprovações em algumas matérias são vistos como fatores sem grande importância nos conhecidos conselhos de classe, que acabam aprovando em massa. Existem casos de diretores que dizem transmitir orientações da própria Secretaria de Educação no sentido de se evitar reprovações, visando aos altos índices de aprovação para as estatísticas oficiais.

Houve uma nítida desvalorização da chamada, do dever de casa e da prova, três mecanismos encarados como sinalizadores do tradicionalismo. O que poderia ser um motivo de alegria para os educadores que buscam a renovação da educação, na verdade acaba sendo um fator adicional de desagregação e improdutividade na escola pública. 
A chamada poderia ser substituída pelo estímulo à presença, fator fundamental para qualquer ação pedagógica participativa, a partir de um processo que levasse em conta o repertório e o interesse do estudante. $\mathrm{O}$ dever de casa poderia ser considerado um conjunto de exercícios, voltados para o aprofundamento daquilo que se estudasse na sala de aula, com abertura para as contribuições espontâneas dos estudantes, ainda mais com as relativas facilidades da parte dos que têm acesso à internet. A prova poderia ser substituída por diversos instrumentos de verificação da aprendizagem para uma avaliação criteriosa, com o sentido de sinalizar em que o estudante deve melhorar, a partir de objetivos devidamente explicitados no início do processo.

Mas não é isso que ocorre. Abandonados os mecanismos tradicionais, prevalecem aqueles que tornam mais fácil a vida do estudante e do professor, diante da dispersão, da agressividade, da falta de motivação, da desvalorização do que a escola oferece (ainda) e pode oferecer.

O que os estudantes desejam realmente? Diante da crise, caberia acabar com a escola, eliminar os professores, formando grupos que buscariam construir conhecimento, livremente? Deve-se promover somente educação informal, com cada pessoa se virando para assimilar informações, desenvolver capacidades, compor sistemas de valores, visões de mundo, espontaneamente, sem direcionamentos? Nesse caso, todos os setores da população teriam acesso às fontes de informação? Como desenvolver capacidades, sem ambientes apropriados e sem orientação de pessoas mais experientes?

A existência da escola, na verdade, não impede a adoção de nenhum outro caminho que considere os mais diversos espaços e sistemas de aprendizagem. Ainda que não deixe de ser também um aparelho ideológico e um instrumento das elites que buscam controlar as instâncias de poder, muitas vezes para se apropriar do bem público, a escola pode se configurar como pólo cultural, certamente com suas contradições, presentes em toda organização social. Além dos ganhos intelectuais em todas as áreas de conhecimento que podem ser proporcionados pelas escolas, elas se constituem numa rede pronta para a efetivação de políticas culturais de dinamização e fruição da criação artística.

Ainda é na escola pública que a população menos contemplada com os bens econômicos, materiais e culturais pode encontrar referências significativas. Isso não exclui a necessidade de sempre se buscar seu aperfeiçoamento organizacional e curricular. A inclusão da arte é sem dúvida um dos fatores importantes para esse aperfeiçoamento. 
As boas condições para o ensino-aprendizagem de teatro, e de arte em geral, não vão ser simplesmente concedidas. Terão que ser conquistadas e o preparo teórico dos professores é fundamental para a argumentação, nas reuniões com os pares e perante os ocupantes de cargos diretivos. Numa sociedade baseada na dominação, expressa pela concentração de riquezas por poucos e pela miséria de grande parte da população, não interessa a quem está no poder a formação integral do cidadão, leia-se o desenvolvimento do ser nos domínios cognitivo, psicomotor, afetivo e estético. É isso que a arte na educação promove, sem limitar-se a desenvolver apenas a razão. Claro que não interessa aos políticos e administradores corruptos governar gente sensivel e sabida.

O professor de Teatro necessariamente é pedagogo e é encenador. Mais que os professores de outras matérias, ele precisa ser um pouco ator e precisa ter algo também de dramaturgo, para organizar os textos saídos de improvisações e fazer adaptações. Diante dos dramas da cena e da vida real que afloram em classe, chega a atuar como psicólogo, e não pode se descolar de sua condição de cidadão e ser político. Como se omitir exercendo uma profissão voltada para o atendimento de uma necessidade tão básica na sociedade? A quem interessa desmoralizar um profissional que tem uma função dessas, e destruir seu espaço de atuação?

Considerar o estudante da escola pública como caso perdido, desinteressar-se pela efetiva aprendizagem, faltar aulas, sair de baixo, em outras palavras, é, efetivamente, reforçar a condição de miséria e contribuir com a dominação. Cabe, portanto, conhecer as regras, identificar parceiros confiáveis nas diversas instâncias da organização social e entrar no jogo para enfrentar a problemática e promover a transformação desejada. 